\title{
MENTAL MODELS FOR LEADERSHIP EFFECTIVENESS: BUILDING FUTURE DIFFERENT THAN THE PAST
}

\author{
Maša MAGZAN \\ Zagreb School of Economics and Management, 10000 Zagreb, Jordanovac 110, Republic of Croatia \\ E-mail: $\underline{\text { masa.magzan@ @sem.hr }}$
}

Accepted 15 November, 2012

\begin{abstract}
This paper focuses on the link between mental models and leadership effectiveness. Reporting from different examples of mental models representing barriers for change, strategic implementation and organizational learning, the paper emphasizes the fact that mental models affect both leadership effectiveness and overall organizational development. Starting from the question what are mental models and why they represent a relevant management issue, the study focuses on the role and meaning of mental models in terms of their influence on organizational outcomes rather than the actions or decisions being made. Within descriptive mode of analysis, the study investigates how mental models affect organizational conversations through mechanisms such as theories in use and espoused theories. The goal of the paper is to demonstrate the need to move from the old paradigm and make a shift toward new mental models because they offer more valid and useful ways to effectively deal with the complex challenges in an increasingly competitive business environment.
\end{abstract}

Key words: mental models, espoused theory, theories in use, leadership effectiveness, organizational learning.

\section{INTRODUCTION:}

What are Mental Models and Why are They Important in Leadership?

Mental models are representations of reality that people use to understand specific phenomena. They represent deeply ingrained assumptions or generalizations that influence how we understand the world and how we take action. These deeply held internal images of how the world works are developed overtime through the proces of socialization, including education, experience and interaction with others. Mental models are very often hidden and we are not consciously aware of our mental models or the effects they have on our behavior. Once created, they become fixed and reinforced in the mind, becoming difficult to change. The function of mental models is to "mediate reality for our minds and help us categorize and organize an endless stream of information we take every day.' (DeBono, 1991).

Mental models can also be defined as 'frameworks' or meaning structures for "describing the interrelationship between activities, objects and abstract items of knowledge in a person's mind, and can also involve prediction of future events" (Johnson-Laird, 1983). These 'cognitive maps', 'schemas' or 'mental constructs' have been studied by cognitive scientists in their attempt to better understand how humans know, perceive, make decisions, and construct behavior in different environments. Johnson-Laird (1983) proposes mental models as the basic structure of cognition: "It is now plausible to suppose that mental models play a central and unifying role in representing objects, states of affairs, sequences of events, the way the world is, and the social and psychological actions of daily life." Some other words used to signify deeply held beliefs, images, assumptions we hold about ourselves, our world and our organizations, are generalizations, cognitive distortions, paradigms, perspectives, beliefs, meaning structures or mind sets.

Since the idea of mental models is very practical and has numerous implications for our lives, schools, businesses and different aspects of social life, mental models have been used in many contexts and for many purposes. They represent a relevant management issue because they affect our both our reasoning and behavior. Numerous research findings 
used for the purpose of this study suggest that mental models have much more influence over the organizational outcomes than the actions or decisions being made.

This is because mental models provide a framework for the interpretation of ideas and activities, assist in restructuring existing information and aid in the inculcation of new information, (Stevenson and Warn, online resource). Despite the fact that there is a direct link between leadership effectiveness and mental models, a vast majority of leadership development opportunities still focus on individuals supporting them to "develop critical skills that make them more effective leaders in their organizations." (Meehan and Reinelt, 2010). This is because leaders are generally held responsible for providing results, and as Thinking-Action-Outcomes Model below suggests, results are determined by actions that leaders take (Figure 1).

For this reason, most leadership and organizational development courses or trainings focus on activities such as goals setting, motivating and inspiring people, coping with conflicts etc. Although possessing these skills is necessary, it is certainly not sufficient for leadership effectiveness. Great leadership requires that leaders challenge their own mental models, and that is the assumptions, beliefs, values and perceptions because both, our decision making and actions are determined and guided by our mental models. Also, great leaders understand that their mental models have much more influence over the outcomes than their actions or decisions being made.

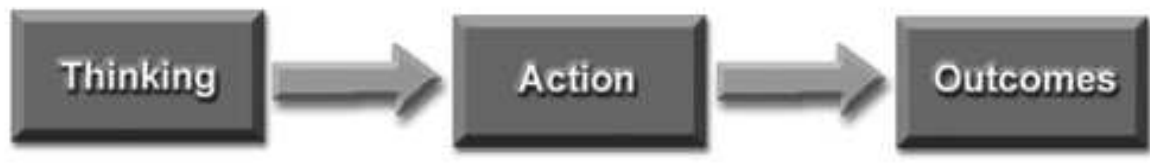

Figure 1: Thinking-Action-Outcomes Model (source: http://whitewatercg.com/2011/04/leadership-models/)

In other words, using the Thinking-ActionOutcomes Model to explain the importance of mental models for leadership effectiveness: the way we see our world (mental models) affects our thinking and experience of the world and therefore determines our actions. When the way we see our world changes (our mental models are challenged and changed), we can then change our actions and get very different results. Unlike reacting which occurs when we respond to a new condition by doing what we have always done, Senge and other thought leaders (Argyris,1990, 1993; Scharmer, 2009; Wheatley, 1992, 2005) suggest that we should respond to change by questioning our mental models. In this process called Reframing (Scharmer, 2009), our deeply held assumptions and governing variables are examined. Only after the underlying assumptions are known and questioned, we can open ourselves to new ways of seeing.

\section{MENTAL MODELS AS BARRIERS TO CHANGE}

\section{"Insanity is continuing to do the same thing over and over and expecting different results." Albert Einstein}

Up to this time, all our organizations have been constructed on notions derived from 17th century Newtonian physics and on assumptions that our world is a world of things, mechanics, hierarchies, and rigid organizations (Wheatley, 1992, 2005). We have learned to believe that the world is stable, linear and predictable. We believe that fixed structures provide clarity and order, but the fact is that they typically function only within the finite contexts for which they were designed. When new conditions arise, such as highly complex challenge of globalization or global financial crisis, they can easily fail because they fail to adapt to the rapidly changing and complex external environment. Due to commonly rooted ways of viewing the world, organizations frequently see solutions to their problems limited only by resources, whether time, personnel, or money.

Although the term 'mental model' was first mentioned in 1940's, in the book „The nature of explanations" by Scottish psychologist Kenneth Craik who believed that the mind constructs "smallscale models" of reality that it uses to anticipate events, to reason, and to underlie explanation, the idea of mental model is not new. Much earlier in history, in his well-known dialogue The Republic, Greek philosopher Plato tells a Parable of the Cave in which he concludes that we are all misguided cave dwellers, operating under incomplete or distorted perceptions of reality. The point of the story is that humans are very resistant to challenge and change their own perceptions of reality. In other 
words, what Plato is pointing out is that due to our mental models, we refuse to change.

Since our social conditioning provides us with a stable environment, mental models function as 'filters' in our brain that allow only certain limited portion of the external stimuli to actually enter our brain. This is useful in terms of filtering information for our sanity and risk reasons, but the problem is that humans generally have a tendency to reject data that does not support an already existing assumption. In other words, the trouble begins when we begin to comprehend everything through categories that worked for us in the past. For this reason, mental models are often the greatest barriers to implementing new ideas in organizations, but they are also the area of organizational learning where organizations can make the most significant impact.

For the same reasons, many good ideas in organization never go through because they simply do not match prevailing ideology or assumptions and beliefs. The examples of successful companies are those that are not afraid to introduce new models of thinking. Such examples are Apple's innovation strategy and design thinking or Dell Computer that completely changed the idea of computer selling and distribution. In this sense, mental models are "equivalent to the concept of paradigm because both paradigm and mental models represent an integrative set of ideas and practices that shape the ways people view and interact with the world." (Senge, online resource).

Managers often get locked into a mindset due to which they tend to filter out information that does not fit their current paradigm. In order to avoid this, managers have to break the old paradigm and step outside their preconceived mental models to keep pace with an ever changing reality. By becoming "paradigm-busters" (Senge, online resource), managers are equipped to constantly challenge and rebuild them in order to imagine 'new ways to understand the world that do not logically follow from past beliefs' (De Wit and Meyer, 2004). If mental models are left unchallenged, they will cause us to see what we have always seen: the same results, the same needs and the same opportunities. Simply because we see what our mental models permit us to see, we can only do what our mental models permit us to do. For this reason, we must first discover what our internal assumptions are. And then unlearn what we think we know.

\section{MENTAL MODELS AS ORGANIZATIONAL LEARNING BARRIERS}

\author{
"Today knowledge has power. It controls access to \\ opportunity and advancement." \\ Peter Drucker
}

Management of the $21^{\text {st }}$ century is about change and learning. As technology and information continue to reshape our lives, managers are becoming change agents who guide everyone to find and embrace the best new practices. Also, as information becomes the chief product of every business and as knowledge continues to explode, everyone has to be a learner and the manager's foremost task is to promote learning. Peter Senge, Chris Argyris, Peter Drucker, Donald A. Schön and Ikujiro Nonaka are the main contributors in the field of learning organization. These are "organizations where people continually expand their capacity to create the results they truly desire, where new and expansive patterns of thinking are nurtured, where collective aspiration is set free, and where people are continually learning how to learn together" (Senge, 1990).

A learning organization represents a great tool for managers because it helps employees to learn more about the products and processes within their organizations and others in order to remain competitive and answer the challenges in the contemporary fast-changing business environment. Since the greatest constant of modern times is change, companies today must learn faster than their competitors in order to maintain ahead of the game. A learning organization becomes imperative because it enables employees or members to continuously share and obtain new knowledge while applying their new found knowledge in doing their work or making organizational decisions. According to Peter Senge (1990), an ensemble of disciplines must converge in order to form a learning organization. It is beyond the scope of this study to describe each one of these dimensions, so the focus will stay on the mental models as one of the basic components that create a learning organization.

Since mental models represent the assumptions held by organizations and individuals which determine how an organization thinks and acts, they can be a barrier for organizational learning. Affecting both, decision making and implementing strategic orientation, mental models can damage overall organizational development. It is important to distinguish here between what Senge calls espoused theories and theories-in-use. Espoused theory relates to what we say we do while theory-in-use is what we 
actually do (based on our own mental models). For instance, an organization or an individual may say that teamwork and collaboration is a primary value (this can even be included in company's official vision or mission statement). Here an espoused theory is that collaboration and teamwork are beneficial, although in reality the same organization may create blocks for collaboration efforts and silo information, only sharing part of the information available. As the model below suggests, a good way to shift from commonly held and not-so-useful mental models is through reflective conversation.
Leaders should facilitate this practice by regularly asking people in a company about what is working and what is not. A company that enforces such conversations is a learning organization because they have embraced the idea that being a learning organization is a good thing so learning becomes a mental model in itself.

Figure 2. shows 3 core learning capabilities of any organization and reflective conversation is one of these.

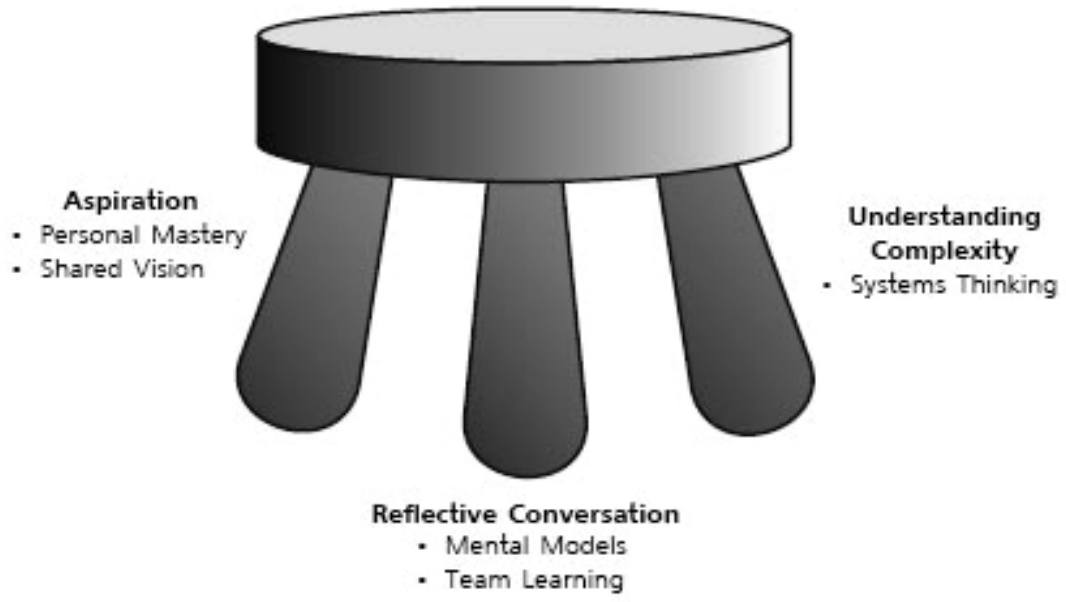

Figure 2: Core Learning Capabilities of Organization (Senge, 1994)

Another important part of reflective conversations for organizational learning is the role of teams. Senge finds that "teams, not individuals, are the fundamental learning unit in modern organizations." (Senge, 1990). He emphasizes that the dialogue among the members of the team increases the ability of the organization to grow and develop. Drawing on conversations with David Bohm, Senge identifies three conditions which are necessary for dialogue: participants must "suspend their assumptions;" they must "regard one another as colleagues;" and there must be a facilitator to hold the context of the dialogue (facilitator is needed at least until teams develop dialogue skills)." Bohm claims that "hierarchy is antithetical to dialogue, and it is difficult to escape hierarchy in organizations" (Senge, 1990).

It is important to point out here that both hierarchy and patterns of relationships are also derived from people's mental models. Capitalizing on the synergy of the continuous group learning for optimal performance, organizational learning requires that individuals in the organization must be ready and willing to reveal their own individual mental models, compare them and discuss the differences in order to come to a unified perception of what really is. Since teams must manage their relationships, culture and processes if they are to be effective, increasingly, there is an understanding that leadership is a process grounded in relationships that are fluid dynamics, non-directive, and nonunilateral. This is a fundamental shift away from a paradigm only advocating leadership as the skills, qualities and behavior of an individual who exerts influence over others to take action or achieves a goal using their position and authority. (Meehan and Reinelt, 2010).

Furthermore, according Etienne Wenger, a social researcher and champion of communities of practice, learning is best explained as "an interaction among practitioners, rather than a process in which a producer provides knowledge to a consumer" (Cross, online resource). Therefore, organizations per se are not the reason employees learn, they are there to help them learn more effectively. In order to do that, Chris Argyris suggest that organizations should ensure conditions in which people can continuously learn. Such conditions assume that "people must feel secure about offering information, meaning that organizations must be transformed into places where it is safe to tell the truth. When that happens, managers can go about their real business, 
which is managing a company's knowledge, through its people." (Argyris, 1993).

In the context of organizational learning, management becomes an art of managing knowledge. This means that what is being managed are not people per se, but rather the knowledge that they carry. And good leadership therefore means creating the conditions that enable people to produce 'valid knowledge and to do so in ways that encourage personal responsibility.' (Argyris, 1993).

Focusing on the issue of managing knowledge in organizations, in his seminal book "Knowledge for Action" Chris Argyris (1993) talks about two types of organizations coined Model I and Model II organizations. Through these two different types of organizations, Argyris explains how based on prevailing type of mental model, organizations are managing either valid or invald knowledge. The importance of mental model here is that it is reflected in the organization's ability to perform and compete.

According to Argyris, Model I organizations have institutionalized form of self-censorship that is defensive and limits real communication. Instead of telling the truth, only that which institutional culture deems appropriate is spoken. For example, if people believe that sharing bad news at the meeting is going to get them in trouble, they will refrain to do so. As a result, suggests Argyris, the organization receives so-called "invalid" knowledge about its status and overall reality. So when this type of organization is in trouble, and Argyris suggests that is the case with majority of organizations, people working for the organization are so distanced from their own reality that they do not see why is the lack of organizational success happening on the first place. This is because, as Argyris asserts, "although people do not always behave congruently with what they say (espoused theories), they do behave congruently with their mental models (theories in use)" (Argyris, 1993). Model II companies have a better way of communicating because they deal with so-called valid knowledge. This enables them to assess reality more correctly and consequently solve problems more effectively as they come because the prevailing ideology created a culture that enforces organization's ability to learn. This ability is crucial for the survival of organizations in a highly complex and constantly changing business environment because developing capacity to learn enables organizations to solve problems and keep up with the changing context.

\section{MENTAL MODELS AS BARRIES TO STRATEGIC IMPLEMENTATION}

\author{
"The only irreplaceable capital an organization \\ possesses is the knowledge and ability of its people. \\ The productivity of that capital depends on how \\ effectively people share their competence with those \\ who can use it." \\ Andrew Carnegie
}

Organizational studies increasingly show how mental models limit our organizations every day. According to Kohl's article on strategic park planning failure (Kohl, 2006) 'many implementation barriers grow out of managers' assumptions or mental models.' Kohl emphasizes that this lineage of assumptions tying today's planning to several fundamental assumptions originating 300 to 400 years ago. One view explaining modern perception of reality was proposed by Rene Descartes who argued that if one breaks any object or problem down into constituent parts and studies those parts, one can understand the whole. The other is Newtonian orientation and the objective of both is belief that highly complex problems can be understood through reductionism. According to Kohl (2006), many other assumptions and barriers can similarly be tied to these common roots descending all the way back to the Enlightenment.

For example, what many organizations call "planning" is simply a projection of their current mental models into the future. In this case, planning becomes projecting the status quo with a new date. The underlying reason are mental models which limit us to familiar ways of thinking and acting. For this reason, our projections of the future suffer from basic assumptions that are not generally valid. In order to avoid these limitations, every planning procedure must, to some extent, expose and challenge the organization's mental models. This does not mean that all mental models should be changed in a planning procedure, but some of our mental models will have to change in order to prepare the ground floor for changing our future. The most common reaction is that people do not really rethink or 'reframe' the problem so that the underlying pattern of thought remains unchanged. For this reason, resources and time in modern organizations and institutions are mostly spent on reorganizing structures and procedures and reacting on issues. So the most common reason that many innovative ideas fail to be translated into meaningful strategic organizational actions is simply because such ideas do not match dominant mental models. 
The fact is that 'modern systems thinking sees the world not as a group of separate parts related in linear cause-and-effect chains, but as a complex system with multiple feedbacks and delays.' (Kohl, 2006). In order to face this complex system, the leaders and organizations must have the capacity to identify and examine their assumptions or mental models. Only when these assumptions are identified and tested, organizations can 'continuously adapt and improve. Once the mind closes, assumptions grow hard and immobile, and a changing context will pass them by.' (Kohl, 2006). This sounds logical and easy but still, people get locked in their own mental models. According to Chris Argyris, there are two simple but powerful mechanisms that block our mental models and produce what is not intended. On is so-called defensive routines, policies or actions we put in place to prevent ourselves and our organizations from experiencing embarrassment or threat. Defensive routines are 'anti-learning and overprotective' and they are a main obstacle from having an open mind. Argyris also talks about "skilled incompetence." Skilled because one does it without thinking (like riding a bike), and incompetence because it creates results that are not intended (like falling from a bike). In practice, this occurs when environment changes and a person continues on behaving according to the same mental model. Basically,"managers use practised routine behaviour (skill) to produce what they do not intend (incompetence)" (Argyris, 1990). An organization may suffer disastrous consequences of products of skilled incompetence. The only remedy is to find out how deeply ingrained are one's incompetences and to unlearn them.

\section{CONCLUSION}

\section{"Problems cannot be solved at the same level of awareness that created them."}

Albert Einstein

Leadership effectiveness is strongly connected with the ability to learn and change and by thus challenge our own mental models. Only after discovering our internal assumptions, we can create future different than the past. Peter Block, a best selling author covering the topics in organizational development, community building and civic engagement, proposes an invitation that promises something different: ,if we want to create something new, we have to invert our thinking: followers create leaders, students create teachers. It doesn't even matter if that's true or not. It's an incredibly useful exercise, because it changes where you pay attention." (from the interview with Peter Block, online resource).
According to Peter Senge, managing mental models involves identifying, clarifying, and changing one's mental model and its component assumptions (Senge, 1990). It is only through such a process of deconstruction our mental models are challenged and we become able to identify new ways of looking at an old problem. Current socio-political and economic climate requires 'a new approach that necessitates leaders thinking differently about how change occurs and how professionals develop themselves and work with each other' (Meehan and Reinelt, 2010). For example, how can a manager deal effectively with an interpersonal problem in his unit if he has certain opinions about an individual? To be an effective leader requires the discipline of mental models which means being able to modify assumptions in order to show the true causes of problems.

The fact is that leaders today frequently face challenges and opportunities that cannot be adequately addressed by reflecting on the past. Leaders must be able to overcome the limitations of their own mental models to develop 'a new understanding that will ensure the development of innovative, but feasible strategies to deal with an unfolding reality.' (De Wit and Meyer, 2004). In his book, Community: The Structure of Belonging (Berrett-Koehler, 2008), Peter Block suggests that a needed paradigm shift in management is to focus on what we can create, rather than what problems we can solve (Block, 2008). From Block's perspective, this means that in order to create the possibility of a future different than the past, we have to move away from 'low-hanging fruit' and change to higher orders of thinking and understanding. In terms of finding sustainable solutions, this means that our framing and perception of the living system interrelationships has to change - our fragmented worldview needs to be replaced with an integrated whole systems mental model. Since learning involves a 'movement of mind' and through learning we re-create ourselves, the primary task of leaders today is to be learners themselves and to promote and facilitate learning in organizations so that 'people can continually expand their capabilities to understand complexity, clarify vision, and improve shared mental models' (Senge, 1990).

\section{REFERENCES}

Argyris, C. (1990). Overcoming Organizational Defences: Prentice Hall.

Argyris, C. (1993). Knowledge for Action: A Guide to Overcoming Barriers for Organizational Change: Jossey-Bass. 
Block, P. (2008). Community: The Structure of Belonging: Berrett-Koehler.

Cross, J. Workflow Learning Gets Real. Retrieved from http://metatime.blogspot.com/2005/02/workflowlearning-gets-real.html

De Wit, B., \& Meyer, R. (2004). Strategy: Process, Content, Context. London: Thomson.

DeBono, E. (1991). I Am Right, You Are Wrong: Penguin Books.

Drucker, P. F. (1988, January-February). The Coming of the New Organization. Harvard Business Review, 3-11.

Ford, J. K., \& Kraiger, K. (1995). The application of cognitive constructs and principles to the instructional systems model of training: implications for needs assessment, design, and transfer. In C. L. Cooper \& I. T. Robertson (Eds.), International Review of industrial and organisational psychology (Vol. 10). West Sussex: John Wiley \& Sons.

Garvin, D. A. (1993, July). Building a Learning Organization. Harvard Business Review, 47-80.

Johnson, H. H. (2008). Mental models and transformative learning: The key to leadership development? Human Resource Development Quarterly, 19(1), 85-89. doi: 10.1002/hrdq.1227

Johnson-Laird, P. N. (1983). Mental Models: towards a cognitive science of language, inference and consciousness. Massachusetts: Harvard University.

Kohl, J. (2006). Mental Models That Block Strategic Plan Implementation. Reflections: The SoL Journal on Knowledge, Learning and Change, 7(1), 30-42.

Kotter, J. (1996). Leading Change: Harvard Business Review Press.

Meehan, D., \& Reinelt, C. (Producer). (2010, March
2012). Leadership for a New Era Series: A new leadership mindset for scaling social change. Retrieved from http://www.philanthropynewyork.org/s_nyrag/bin. asp?CID=17439\&DID=43967\&DOC=FILE.PDF

Nonaka, I. (2007, July-August). The Knowledge-Creating Company. Harvard Business Review, 162-171.

Otto, S. (2009). Theory U: Learning from the Future as it Emerges: Berret-Koehler Publishers.

Raelin, J. A. (2003). Creating Leaderful Organizations: How to Bring Out Leadership in Everyone. San Francisco: Berrett-Koehler.

Schubert, V., \& Baker, R. (Producer). (2008, June 2012). Creating New Futures Through Community Conversation: An Interview with Peter Block. Retrieved from http://www.pegasuscom.com/levpoints/peterblocki nt.html

Senge, P. (Producer). (March 2012). Learning to Alter Mental Models. Retrieved from http://www.solonline.org/res/kr/mentmodel.html

Senge, P. (1990). The Fifth Discipline: The Art \& Practice of the Learning Organization. New York: Currency Doubleday.

Stevenson, E. J., \& Warn, J. R. (Producer). (March 2012). Effective Leadership Development: creating better mental models. Retrieved from http://www.defence.gov.au/ADC/cdclms/IMTA\%2 0Article.doc

Wheatley, M. J. (1992). Leadership and the New Science. San Francisco: Berrett-Koehler Publishers.

Wheatley, M. J. (2005). Finding Our Way: Leadership for an Uncertain Time. San Francisco: BerrettKoehler. 